\title{
Calculation of Boundary Stripping Ratio Errors at the Stage of Quarries Designing
}

\author{
Alexei Selyukov ${ }^{1, *}$, and Radim Rybár ${ }^{2}$ \\ ${ }^{1}$ T.F. Gorbachev Kuzbass State Technical University, Department of open pit mining, 650000 \\ Kemerovo, 28 Vesennya st., Russian Federation \\ ${ }^{2}$ Technical University of Kosice, 04200 Letná 9, Kosice, Slovak republic
}

\begin{abstract}
The open pit mining method of solid minerals extracting is widely used both in Russia and in the whole world, and sets a general direction of mining industry development as its main tool, at least for the next decades. This is due to its significant advantages compared with other methods of minerals extraction, especially with underground method. This conclusion is made considering production capacity of mining and enrichment enterprises, mining safety, productivity and working conditions, investment and operating costs, level of mechanization, automation, robotization, informatization and computerization of production, full use of mineral resources. However, the practical realization of these advantages of the open pit method of mining, neutralization and reduction or elimination of its shortcomings (environmental damage) requires thorough and reliable design solutions, their timely and accurate adjustment, application of scientific methods and modern technical and technological means. This is especially important and relevant for design, construction, operation, reconstruction and reclamation of open pits developing complex and large deposits of scarce and valuable mineral resources. Erroneous and insufficiently substantiated design solutions and their implementation lead to a significant decrease in the efficiency of open pit mining.
\end{abstract}

\section{Introduction}

At open pit mining (as compared to underground mining), it is easier to follow the changing form of deposits. This fact gives more opportunities for selective extracting and averaging the quality of commercial mineral products, i.e. there are more opportunities for the full use of the wealth of mineral resources [1-4]. In many cases, it is possible to build an open pit mine with predetermined main parameters of the quarry field [5]. Therefore we propose to take into account the risks and errors in the calculation methods for assessing the main parameters of the quarry.

\section{Materials and Methods}

According to the existing theoretical provisions [6-8] the final depth of the quarry is determined by the boundary stripping ratio $\left(\mathrm{m}^{3} / \mathrm{t}\right)$, which is an economic indicator. It is

\footnotetext{
*Corresponding author: sav.ormpi@,kuzstu.ru
} 
economically feasible to conduct mining operations to a depth at which the conditions of equality of the boundary and the current stripping ratio are fulfilled. In addition, a very common criterion for the calculation is the maximum profit in the development of the field.

P. I. Gorodetsky successfully developed the idea of maximum profit in the development of the mineral field by the combined method (surface and underground mining). Years after that, this idea was developed by V.S. Khokhryakov, who introduced the time factor, the efficiency of investments and the impact of technological progress as the basic elements of calculations.

According to the methods developed by P.I. Gorodetsky and V.S. Khokhryakov, the increase in profit is achieved by reducing the final depth of quarries and reducing the cost of minerals. Thus, the cost of minerals at open mining compared to underground mining is usually lower by 1.5-1.8 and 1.8-2 times, respectively, according to the methods introduced by P. I. Gorodetsky and V. S. Khokhryakov.

This leads to a strong underestimation of the productivity and boundaries of quarries in the case where it is possible to continue further underground development of the field, and the loss of additional profits can be caused by the growth of production concentration. The deposits for which the option of underground mining is generally unacceptable are in preferable situation. For them the boundaries of the quarry are determined on the basis of profitability.

\section{Results and Discussion}

When determining the boundaries of open pit mining and planning open development of deposits in general, the criterion of maximum profit should be used very carefully, since we are dealing with non-renewable raw materials and need to use them wisely and fully.

As an example, let us consider the distribution curve of the values of the boundary stripping ratio (Fig. 1 (a).

a

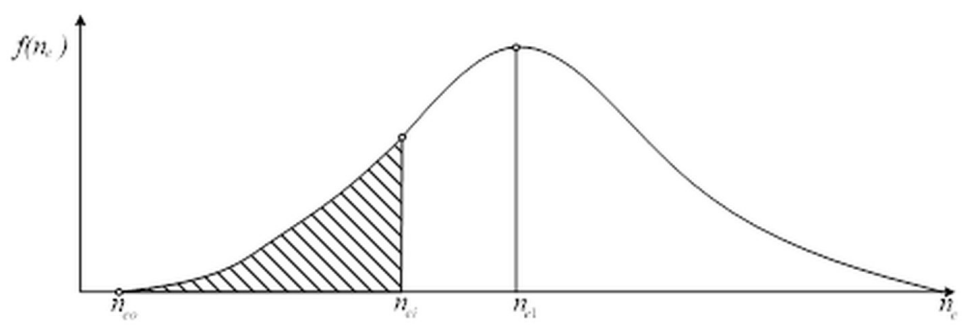

b

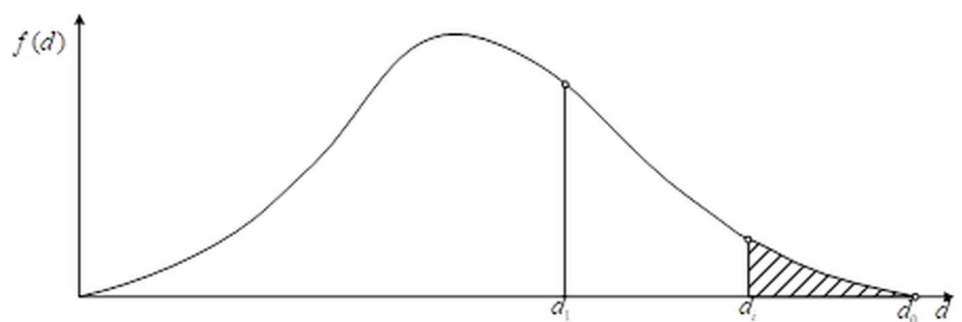

Fig. 1. The distribution graph of possible values of the boundary stripping ratio $n_{e i}$ (a) and the sum $d=n_{0}+n_{l}$ (b). For Fig. 1 the following designations are accepted $n_{e}-$ the boundary stripping ratio, $\mathrm{m}^{3} / \mathrm{m}^{3}$. 
Acceptance in the calculated values of mathematical expectation $n_{e l}$ carries a risk of $50 \%$. It is dangerous to rise the value of ne in the process of calculations. Therefore, to reduce the risk you need to take $n_{e i}<n_{e l}$. At $n_{e}=n_{e 0}$ the risk is zero.

For the case of the normal distribution law, we obtain:

$$
\left.\begin{array}{c}
R=0 ; n_{e}=n_{e 0} \\
R=2.3 \% ; n_{e}=n_{e 0}(1+\sigma) \\
R=15.9 \% ; n_{e}=n_{e 0}(1+2 \sigma) \\
R=25 \% ; n_{e}=n_{e 0}(1+3 \sigma-E) \\
R=50 \% ; n_{e}=n_{e 0}(1+3 \sigma)
\end{array}\right\}
$$

Enter a value of the relative increment of the boundary stripping ratio (compared with the ratio $\left.n_{e 0}\right)$ :

$$
\sigma_{i}=\frac{n_{e i}-n_{e 0}}{n_{e 0}}
$$

The value $\delta 1$ is given in Tab. 1. The definition of a rational level of risk is associated with the assessment of possible consequences of risk.

With regard to the issue of our consideration, it is useful to introduce the consideration of the function $P(\delta)$ of caution of consequences, which is reverse to the evaluation of errors of the utility function. Then, with a cautious attitude to risk:

$$
P_{0}(\sigma)=a\left(e^{\sigma}-1\right)
$$

Table 1. Risk assessment factors.

\begin{tabular}{|c|c|c|c|c|c|}
\hline \multirow{2}{*}{$\begin{array}{c}\text { Coefficient and } \\
\text { its relative } \\
\text { increment }\end{array}$} & $\mathbf{0}$ & $\mathbf{2 . 3}$ & $\mathbf{1 5 . 9}$ & $\mathbf{2 5}$ & $\mathbf{5 0}$ \\
\cline { 2 - 6 } & 3.7 & 4.47 & 5.24 & 5.48 & 6.00 \\
$n_{e}$ & 0 & 0.208 & 0.416 & 0.482 & 0.623 \\
$\delta i$ & 7.53 & 6.41 & 5.59 & 5.28 & 4.88 \\
$n_{0}+n_{l}$ & 0 & 0.149 & 0.258 & 0.299 & 0.352 \\
$\delta i$ & & & & & \\
\hline
\end{tabular}

With safe attitude:

$$
P_{p}(\sigma)=a \sigma
$$

With a bold attitude:

$$
P_{c}(\sigma)=a\left(1-e^{-\sigma}\right)
$$

The graph of the function $P(\delta)$ at $a=1.5$ is shown in Fig. 2 (solid lines). If a bold attitude to take the risk of $50 \%$, i.e. take $\delta c=0.623$ (point 3), the normal level of the function of caution is equal to $P_{N}=0.7$. Safe attitude $\delta p=0.47$ (point 2), with careful $\delta_{0}=0.38$ (point 1 ). Obtained at $P_{N}=0.7$ values of the boundary stripping ratio are shown in Tab. 2.

Let us consider the sum $n_{0}+n_{l}=d$, the distribution curve of which is shown in Fig. $1 \mathrm{~b}$. It is dangerous to decrease the value of $d$ in the calculation process. Therefore, to reduce the risk we should take $d i>d_{l}$. When $d=d_{0}$, the risk is equal to or close to zero.

We introduce the value of the relative reduction of the sum $d$ ' $i$ : 


$$
\delta_{i}^{\prime}=\frac{d_{0}-d_{i}}{d_{0}}
$$

The $d^{\prime} i$ values obtained from Tab. 1 are shown in Tab. 2 .

To proceed to the risk caution functions mapping, it is necessary to consider the value of the proportionality coefficient $a$. Currently, there are no methods for determining this coefficient for different objects. Within the meaning of this coefficient is the price of a unit of relative increase (decrease) of the value of the considered parameter $\delta$.

Thus, the risk values will differ for different parameters, as different economic consequences of errors. Formally, there are two ways to determine the coefficients.

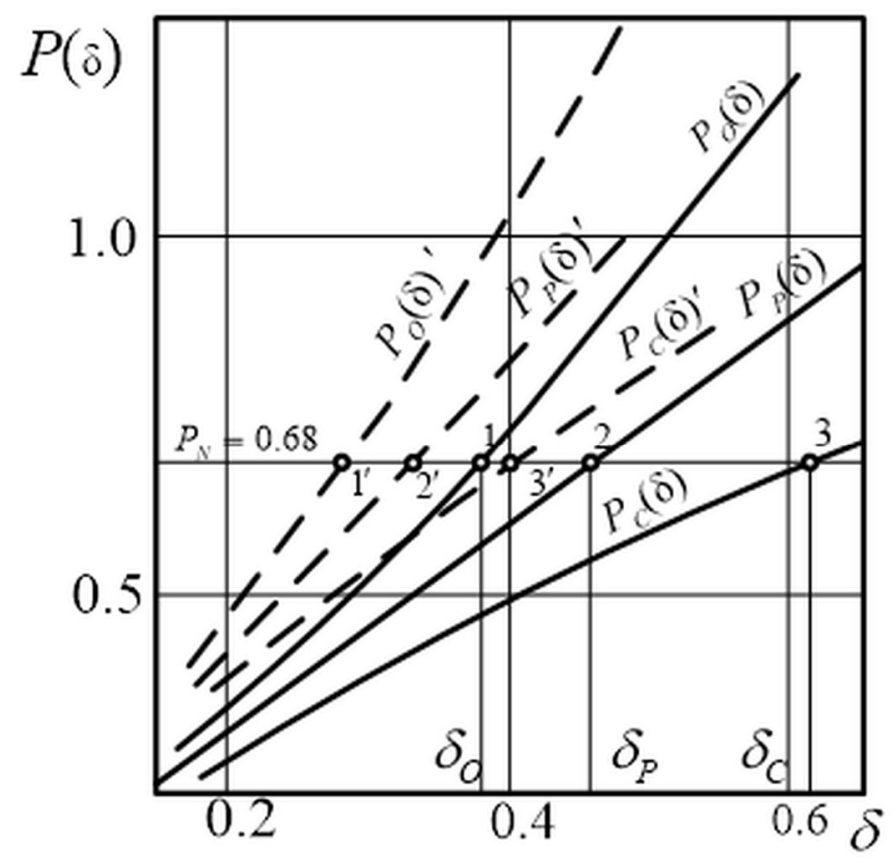

Fig. 2. Graph of the function of the caution of the consequences of increasing the stripping ratio (solid lines) and reducing the amount of $n_{0}+n_{l}$ (dashed lines).

Table 2. The parameters of risk corrective coefficients.

\begin{tabular}{|c|c|c|c|c|c|c|}
\hline $\begin{array}{c}\text { Attitude to } \\
\text { risk }\end{array}$ & $\boldsymbol{\delta}$ & $\boldsymbol{R}, \boldsymbol{\%}$ & $\boldsymbol{n}_{\boldsymbol{e}}, \mathbf{m}^{\mathbf{3} / \mathbf{m}^{\mathbf{3}}}$ & $\boldsymbol{\delta}^{\mathbf{1}}$ & $\boldsymbol{R , \%}$ & $\begin{array}{c}\boldsymbol{n}_{\boldsymbol{o}}+\boldsymbol{n}_{\mathbf{1}}, \\
\mathbf{m}^{\mathbf{3}} / \mathbf{m}^{\mathbf{3}}\end{array}$ \\
\hline $\begin{array}{c}\text { Maximum } \\
\text { risk }\end{array}$ & 0.63 & 50 & 6 & 0.325 & 50 & 4.88 \\
\hline Bold & 0.623 & 50 & 6 & 0.352 & 50 & 4.88 \\
\hline Safe & 0.47 & 23.5 & 5.44 & 0.30 & 26 & 5.27 \\
\hline Careful & 0.38 & 13.5 & 5.1 & 0.26 & 16 & 5.58 \\
\hline No risk & 0 & 0 & 3.7 & 0 & 0 & 7.53 \\
\hline
\end{tabular}


The value of the function of caution with a bold attitude to risk is taken to be the same. Then when $\delta c=0.32$ (see Tab. 1) we have $P_{N}=0.7$. From here, we find that:

$$
a=\frac{0.7}{1-e^{-0.352}}=2.37
$$

It is determined by some method (for example, the method of expert evaluation) with respect to the increase (decrease) in the risk price when determining the amount of $n_{0}+n_{1}$ compared to the $n_{e}$ coefficient. If, for example, $a^{\prime} / a=1.4$, then $d=1.5 \times 1.4=2.1$.

Then the normal level of the caution function will be different for the two parameters under consideration.

More research is needed to clarify these issues. In the first approximation, we take the first way of determining the coefficient $a$, i.e. $a=2.37$. The graph of the function $P(\delta)$ is shown in Fig. 1 (dashed lines). With a bold attitude towards risk and $P n=0.7, \delta^{\prime} c=0.352$. With safe attitude to risk $\delta^{\prime} p=0.3$ (point 2) and with careful $\delta^{\prime} O=0.26$ (point 1 ). The obtained values of the sum $n_{0}+n_{l}$ are shown in Tab. 2 .

We take an safe attitude to the risk. A joint graph of the distribution of these values is shown in Fig. 3 at a risk of $23.5 \%$, we take $n_{e}=5.44 \mathrm{~m}^{3} / \mathrm{m}^{3}$ (point B1), and at a risk of $16 \%$, we take $n_{0}+n_{l}=5.27 \mathrm{~m}^{3} / \mathrm{m}^{3}$ (point B2).

If you focus on a bold attitude to risk $50 \%$, then $n_{e}=6$ and $n_{0}+n_{1}=4.88$, then you can increase the stripping ratio from 4.88 to 6 .

\section{Conclusion}

The definition of rational boundaries of open-pit mines is a very difficult task, the solution of which can not have a quick and direct testing in practice. Its complexity lies in the fact that it initiates surface mine designing as well as brings it to results. This means that the boundaries of open pit mine must be known at the initial stage of quarry design. Therefore, the definition of the boundaries of open pit mine is possible by gradually approaching the initial positions taken intuitively on the basis of engineering experience, to the effective data obtained in the process of detailed calculation. Thus, placing into the basis the objectivity of the boundary stripping ratio, findings the boundaries of open mining can be reduced to the choice of the compared deviation of the error values based on the criteria of mathematical statistics.

\section{References}

1. M. Tyulenev, S. Markov, M. Cehlar, S. Zhironkin, M. Gasanov, Acta Montanistica Slovaca, 23:4, 368-377 (2018)

2. O. Litvin, M. Tyulenev, S. Zhironkin, S. Prokopenko, Acta Montanistica Slovaca, 22:2, 146-152 (2017)

3. M. Tyulenev, O. Litvin, M. Cehlár, S. Zhironkin, M. Gasanov, Acta Montanistica Slovaca, 22:3, 296-302 (2017)

4. T. Gvozdkova, M. Tyulenev, S. Zhironkin, V. A. Trifonov, Yu. M. Osipov, IOP Conf. Ser.: Earth Environ. Sci., 50:1, 012010 (2017)

5. M. Tyulenev, S. Markov, M. Cehlar, S. Zhironkin, M. Gasanov, Acta Montanistica Slovaca, 23:4, 368-377 (2018)

6. A.V. Selyukov, Taishan Academic Forum - Project on Mine Disaster Prevention and Control (2014)

7. A.V. Selyukov, Journal of Mining Science, 51(5), 879-887 (2015) 
8. A.V. Selyukov, Bulletin of the Tomsk Polytechnic University, Geo Assets Engineering, 326:12, 60-71 (2015) 